\title{
Effects of biphasic positive airway pressure in patients with chronic obstructive pulmonary disease
}

\author{
E. Katz-Papatheophilou, W. Heindl, H. Gelbmann, P. Hollaus, M. Neumann
}

\begin{abstract}
Effects of biphasic positive airway pressure in patients with chronic obstructive pulmonary disease. E. Katz-Papatheophilou, W. Heindl, H. Gelbmann, P. Hollaus, M. Neumann. (C) ERS Journals Ltd 2000.

ABSTRACT: Biphasic positive airway pressure (BiPAP) is a ventilatory mode in which two pressure levels (higher $(P$ high) and lower $(P$ low)) acting as continuous positive airway pressure (CPAP) alternate at preset time intervals. BiPAP combines pressure-controlled ventilation with unrestricted spontaneous breathing. BiPAP has not yet been evaluated in patients with chronic obstructive pulmonary disease (COPD).

Therefore, the effects of BiPAP $\left(15 \mathrm{cmH}_{2} \mathrm{O}\right.$ Phigh and $5 \mathrm{cmH}_{2} \mathrm{O}$ Plow $)$ pressure support (PS; $15 \mathrm{cmH}_{2} \mathrm{O}$ and positive end-expiratory pressure (PEEP) $5 \mathrm{cmH}_{2} \mathrm{O}$ ) and CPAP $\left(5 \mathrm{cmH}_{2} \mathrm{O}\right)$ on respiratory mechanics in COPD patients were compared. Twentyone COPD patients were supported in randomized order with BiPAP, PS and CPAP. Pressure-time product (PTP), work of breathing (WOB), change in oesophageal pressure $(\triangle P$ oes $)$, mouth occlusion pressure $(P 0.1)$, intrinsic PEEP (PEEPi), tension time index (TTI), respiratory frequency, and tidal volume $(V T)$ were measured.

During BiPAP, the COPD patients showed a significantly higher PTP, WOB, $\triangle P$ oes, P0.1, TTI and PEEPi than during PS. Comparing the Plow phases of BiPAP and CPAP, the breaths during the $P$ low phases of BiPAP had a lower $V T$ and a greater WOB and PTP due to a higher PEEPi than on CPAP alone.

In conclusion, biphasic positive airway pressure carries the risk of increased work of breathing in spontaneously breathing chronic obstructive pulmonary disease patients. Pressure support is superior for reducing their respiratory muscle effort. Eur Respir J 2000; 15: 498-504.
\end{abstract}

Pulmologisches Zentrum der Stadt Wien, Intensivstation, 1 interne Lungenabteilung, Vienna, Austria.

Correspondence: E. Katz-Papatheophilou Pulmologisches Zentrum der Stadt Wien Intensivstation

1 Interne Lungenabteilung

Sanatoriumstraße 2

A-1145 Wien

Austria

Fax: 4319106049853

Keywords: Biphasic positive airway pressure

chronic obstructive pulmonary disease

Received: June 111999

Accepted after revision December 101999
Treating patients with chronic obstructive pulmonary disease (COPD) in acute on chronic respiratory failure is a challenging task in intensive care medicine. The imbalance of the increased load on the respiratory muscles and their decreased capacity leads to pump failure, requiring mechanical ventilatory support. Various modes of partial ventilatory support have proven their ability to diminish respiratory muscle effort. Continuous positive airway pressure (CPAP) reduces the patient's work of breathing (WOB) by counterbalancing the intrinsic positive end-expiratory pressure (PEEP) (PEEPi) and thus unloading the inspiratory muscles [1]. Pressure support (PS) ventilation is a well-known standard mode for decreasing respiratory muscle effort by adding an inspiratory pressure to every single breath. Supporting the inspiratory muscles with PS increases the tidal volume $(V \mathrm{~T})$, decreases the respiratory frequency $(f R)[2-4]$ and also compensates for the extra work caused by the endotracheal tube [5]. PEEP is used additionally to reduce the WOB component caused by the PEEPi $[6,7]$.

A newer ventilatory mode called "biphasic positive airway pressure" (BiPAP) was developed by BAUM et al. [8] and introduced into clinical practice in the late 1980s. The principle of BiPAP is the combination of pressurecontrolled ventilation and spontaneous breathing. This is realized by two different PEEP-levels (higher $(P$ high $)$ and lower (Plow)) which alternate at preset time intervals (duration of $P$ high (thigh) and duration of $P$ low (tlow)) to permit passive ventilation of the lung. Additionally, the patient can breathe spontaneously at both PEEP levels in a CPAP system (fig. 1). These spontaneous breaths are unrestricted in each phase of the ventilatory cycle. Thus BiPAP simultaneously combines pressure-controlled timecycled mechanical ventilation and independent spontaneous CPAP breaths. It is closely related to airway pressure release ventilation, which also allows spontaneous CPAP breaths at a high pressure level.

BiPAP can improve the ventilation/perfusion distribution [9-12] and decrease the consumption of sedatives and narcotics [13]. BiPAP has become a valuable mode, particularly in ventilating patients with adult respiratory distress syndrome (ARDS) $[9,14]$. It can be applied along with full respiratory support in sedated patients, but also in partial assist mode in spontaneously breathing patients. Due to this variety of uses, BiPAP was regarded as a suitable mode for the entire period of mechanical ventilation without the necessity of switching modes [15]. BiPAP is used frequently, especially in ARDS and post-surgery patients [13], but its efficiency in COPD patients has not 

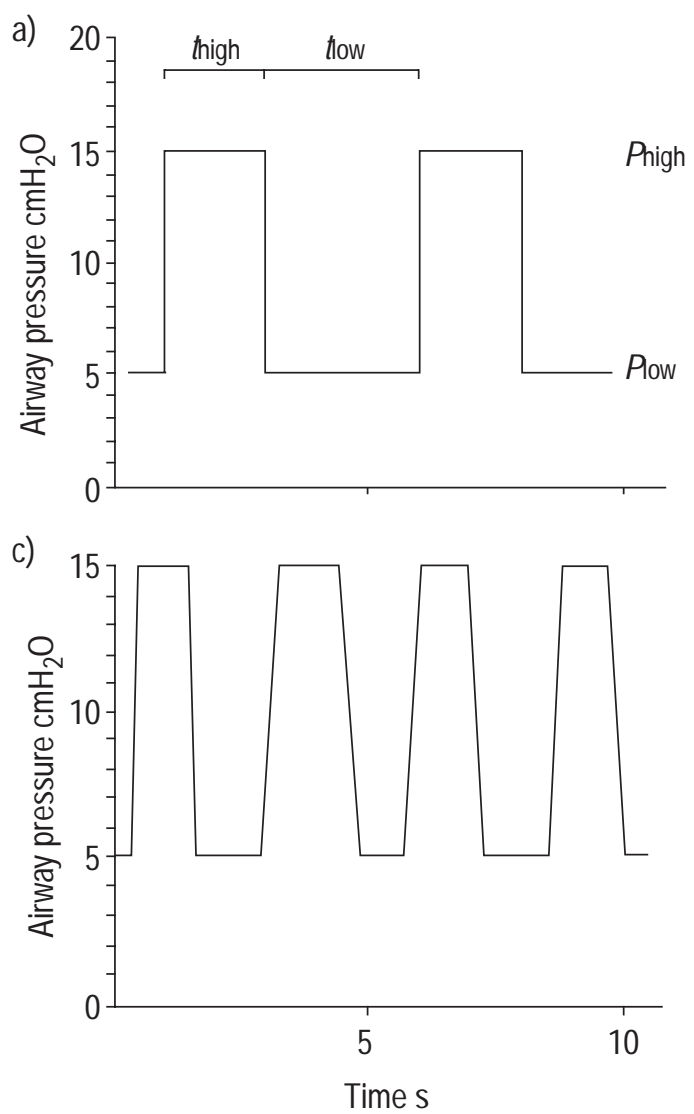

b)

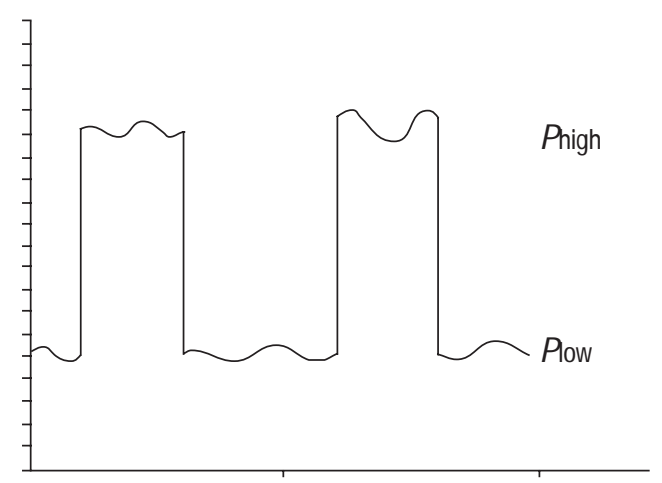

d)

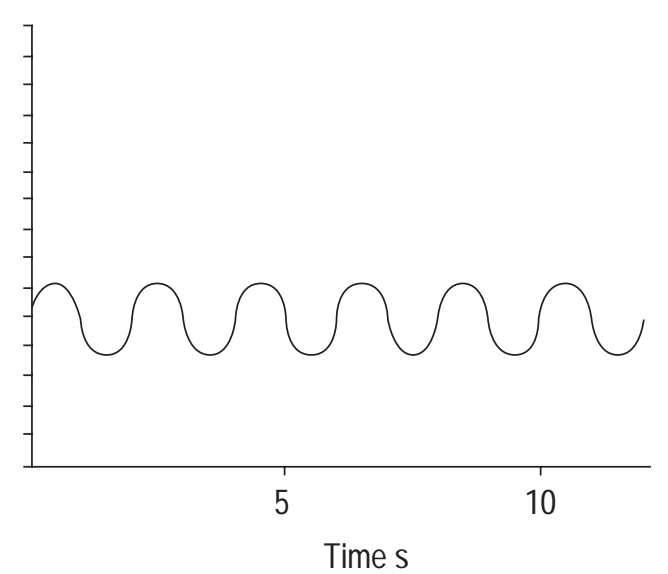

Fig. 1. - Ventilator systems. Biphasic positive airway pressure (BiPAP) a) without (pressure-controlled time-cycled mechanical ventilation) and b) with ("classical BiPAP" with unrestricted spontaneous breaths at both pressure levels) spontaneous breaths. c) pressure support (every single breath is pressure-assisted) d) continuous positive airway pressure (spontaneous breaths at one pressure level without pressure-assist). $P$ high: higher positive endexpiratory pressure (PEEP) level; Plow: lower PEEP level; thigh: duration of Phigh; tlow: duration of $P$ low.

yet been evaluated. The aim of the present study was to find out how BiPAP affects respiratory mechanics in spontaneously breathing COPD patients.

\section{Subjects and methods}

\section{Study population}

In order to address this question, 21 patients with COPD, who were intubated and on mechanical ventilation because of acute respiratory failure, were studied. At the time of the study, all patients were still intubated and breathing with ventilatory assistance, fully conscious, cooperative and in stable respiratory and haemodynamic condition. Each patient was ventilated with PS, BiPAP and CPAP in random order, while various data concerning respiratory muscle effort were continuously measured. Each patient had consented and the study was approved by the local ethical committee. Patient characteristics are shown in table 1.

\section{Measurements}

The study was conducted with the patients in a semirecumbent position. An oesophageal balloon catheter (SmarthCath Esophageal Catheter; BICORE, Irvine, CA, USA) was inserted and connected to a bedside intensive care unit (ICU) monitor and calculator (CP-100 Pulmonary Monitor; BICORE). A flow sensor (VarFlex Flow Transducer; BICORE) was placed between the endotracheal tube and the Y-piece of the ventilator circuit and also connected to the CP-100 device. The CP-100 system was developed for continuous bedside monitoring of pulmonary mechanics in ICU settings. It performs calculations in conformity with the literature and has been applied in several published scientific studies [16-18].

After calibration, checking the correct positioning of the oesophageal catheter by means of the "occlusion test" [19] and performing a leak test, the following data were measured or calculated with the pulmonary monitor breath by breath.

From the flow sensor, airway pressure, flow, $f \mathrm{R}$, inspiratory time $(t \mathrm{I})$ and total respiratory cycle duration (ttot) were obtained. The respiratory time fraction $(t \mathrm{t} / t$ tot $)$ was calculated. The $V \mathrm{~T}$ was obtained by integrating the flow signal. The change in oesophageal pressure $\left(\Delta P_{\text {oes}}\right)$ was measured as the negative change in the $P_{\text {oes }}$ from the measured $P$ oes plateau to the minimum value. The PEEPi [20-23] was measured as the amount of negative deflection of the $P_{\text {oes }}$ preceding the start of inspiratory flow. The mouth occlusion pressure $P_{0.1}$ [24] was measured in terms of the change in $P$ oes during the first $100 \mathrm{~ms}$ of inspiratory effort using the quasi-occlusion technique. The patient's WOB $[25,26]$ was obtained by integration of the negative $P_{0 e s}$ 
Table 1. - Characteristics of patients in study

\begin{tabular}{|c|c|c|c|c|c|c|c|c|}
\hline $\begin{array}{l}\text { Patient } \\
\text { No. }\end{array}$ & $\begin{array}{l}\text { Age } \\
\text { yrs }\end{array}$ & Sex & $\begin{array}{l}\text { Height } \\
\mathrm{cm}\end{array}$ & $\begin{array}{l}\text { Weight } \\
\mathrm{kg}\end{array}$ & Diagnosis & $\begin{array}{l}\mathrm{MIP} \\
\mathrm{cmH}_{2} \mathrm{O}\end{array}$ & $\begin{array}{l}\text { Duration of } \\
\mathrm{MV}^{+} \text {days }\end{array}$ & Outcome \\
\hline 1 & 68 & $\mathrm{M}$ & 173 & 78 & COPD, achalasia & -51 & 48 & Discharged \\
\hline 2 & 64 & M & 163 & 54 & COPD, pneumonia, alcoholism & -33 & 36 & Died* \\
\hline 3 & 52 & $\mathrm{M}$ & 170 & 65 & COPD, Stp. cerebral apoplexia & -49 & 4 & Discharged \\
\hline 4 & 79 & M & 170 & 70 & 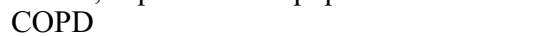 & -42 & 13 & Died** \\
\hline 5 & 48 & $\mathrm{~F}$ & 165 & 80 & COPD & -92 & 13 & Discharged \\
\hline 6 & 73 & $\mathrm{~F}$ & 160 & 89 & COPD & -36 & 23 & Discharged \\
\hline 7 & 45 & M & 175 & 58 & COPD, lung carcinoma, Stp bilobectomy & -31 & 33 & Discharged \\
\hline 8 & 64 & M & 170 & 53 & $\begin{array}{l}\text { COPD, lung carcinoma, Stp } \\
\text { pneumonectomy }\end{array}$ & -40 & 19 & Discharged \\
\hline 9 & 70 & $\mathrm{~F}$ & 162 & 63 & COPD, nosocomial pneumonia & -26 & 24 & Discharged \\
\hline 10 & 73 & M & 165 & 65 & COPD, pneumonia & -64 & 3 & Discharged \\
\hline 11 & 59 & $\mathrm{M}$ & 180 & 90 & COPD, pneumonia, pulmonary embolism & -42 & 23 & Discharged \\
\hline 12 & 51 & $\mathrm{~F}$ & 155 & 49 & COPD, pneumonia & -49 & 6 & Discharged \\
\hline 13 & 73 & $\mathrm{~F}$ & 157 & 49 & COPD, haemoptysis, Stp tuberculosis & -34 & 21 & Died*** \\
\hline 14 & 64 & $\mathrm{M}$ & 170 & 96 & COPD & -56 & 5 & Discharged \\
\hline 15 & 48 & $\mathrm{~F}$ & 164 & 40 & COPD, Stp volume-reduction & -48 & 8 & Discharged \\
\hline 16 & 56 & $\mathrm{M}$ & 181 & 72 & COPD & -52 & 13 & Discharged \\
\hline 17 & 70 & M & 170 & 86 & COPD, pneumonia & -67 & 10 & Discharged \\
\hline 18 & 69 & $\mathrm{~F}$ & 165 & 80 & COPD & -51 & 10 & Discharged \\
\hline 19 & 71 & $\mathrm{M}$ & 168 & 58 & $\begin{array}{l}\text { COPD, Stp cardiopulmonary arrest, } \\
\text { acute renal failure }\end{array}$ & -88 & 24 & Discharged \\
\hline 20 & 77 & $\mathrm{~F}$ & 155 & 58 & COPD & -43 & 11 & Discharged \\
\hline 21 & 56 & M & 180 & 93 & COPD, acute renal failure & -43 & 56 & Discharged \\
\hline $\operatorname{Mean} \pm \mathrm{SD}$ & $63.3 \pm 10.3$ & & $167 \pm 7.6$ & $68.8 \pm 16.3$ & & $-49.3 \pm 16.9$ & $19.1 \pm 14.2$ & \\
\hline
\end{tabular}

${ }^{+}$: from intubation until extubation; *: ventilator-associated pneumonia with sepsis; $* *$ : acute myocardial infarction; $* * *$ : massive haemoptysis with cardiac arrest. MIP: maximal inspiratory pressure; MV: mechanical ventilation; M: male; F: female; COPD: chronic obstructive pulmonary disease; Stp: status post

during inspiration multiplied by the flow plus chest wall work divided by the $V$ T. The onset of inspiration was determined using the Poes curve, so that the PEEPi component was included. The pressure-time product (PTP) [27] was measured by calculating the integral of $P_{\mathrm{oes}}$ and the duration of contraction of the inspiratory muscles. The onset of inspiratory muscle contraction was determined by the sharp decline on the Poes curve, thus including the PEEPi component. Further, the quotient $\mathrm{PTP} / V \mathrm{~T}$ was evaluated in order to get information about the efficiency of the breaths. The same PTP can be used to produce either a large or a small $V \mathrm{~T}$. The first case is an economical investment of metabolic work; the second means much effort for little output. A modified tension-time index TTI [28-30] was calculated using the formula $\mathrm{TTI}=\Delta P_{\mathrm{oes}} /$ maximal inspiratory pressure $(\mathrm{MIP}) \times t \mathrm{I} / t$ tot. MIP was measured as follows: the patient's airway was occluded at functional residual capacity and the patient requested to inspire maximally against the occlusion. The maximum deflection of the $P$ oes indicated the MIP. This procedure was performed three times and the highest value reported.

\section{Study protocol}

Each patient was ventilated in random order using three different modes: PS, CPAP and BiPAP, (EVITA ventilator; Drägerwerk, Lübeck, Germany). The inspired oxygen fraction was adapted individually to each patient in order to maintain an arterial oxygen saturation of $\geq 95 \%$ and was not changed during the three modes. The ventilator settings were chosen using the following criteria: a PEEP of 5 $\mathrm{cmH}_{2} \mathrm{O}$ for all three modes, equal mean pressures for BiPAP and PS; a Phigh for $2 \mathrm{~s}$ during BiPAP, as recommended [8] to allow spontaneous breaths at $P$ high as well; and a mandatory frequency of 12 breaths $\cdot \mathrm{min}^{-1}$ during BiPAP, as it is frequently used in sedated patients before they start spontaneously breathing. The exact ventilator settings were (see also fig. 1): PS: PS $15 \mathrm{cmH}_{2} \mathrm{O}$ and PEEP $5 \mathrm{cmH}_{2} \mathrm{O}$; CPAP: PEEP $5 \mathrm{cmH}_{2} \mathrm{O}$; and BiPAP: Phigh $15 \mathrm{cmH}_{2} \mathrm{O}$, Plow 5 $\mathrm{cmH}_{2} \mathrm{O}$, thigh $2 \mathrm{~s}$, and tlow $3 \mathrm{~s}$. The mean pressures were taken from the ventilator display and were $9.02 \pm 1.7 \mathrm{cmH}_{2} \mathrm{O}$ for PS and $9.28 \pm 1.6 \mathrm{cmH}_{2} \mathrm{O}$ for BiPAP, the difference was not statistically significant (Student's t-test).

Entering the study, all the patients were stable on PS with $20 \mathrm{cmH}_{2} \mathrm{O}$. They were randomized into one of six treatment possibilities: PS-CPAP-BiPAP, PS-BiPAP-CPAP, CPAPBiPAP-PS, CPAP-PS-BiPAP, BiPAP-CPAP-PS, and BiPAP-PS-CPAP. After the patient had been switched to the first ventilatory mode and was breathing quietly, measurement of the above mentioned parameters was commenced breath by breath for 15-min. All data were recorded on a personal computer connected to the BICORE monitor. At the end of the 15-min period, arterial blood was withdrawn from an arterial catheter and analysed using a blood gas analyser (AVL 995-Hb, AVL Medical Instruments, Graz, Austria). The patient was then switched to the next ventilatory mode and the same procedure was repeated. Finally, the third mode was applied and the measurements were obtained in the same way. The total recording time per patient was, therefore, $45 \mathrm{~min}$, except in patients No. 6, 9, 12 and 18, who experienced severe dyspnoea on CPAP and BiPAP, and for whom the recording time ended with complaint a few minutes earlier. These patients had prolonged resting times of $\sim 15-45 \mathrm{~min}$ between the study phases and were not switched to the next mode until they had recovered 
and felt comfortable again. All patients were monitored continuously during the study and no haemodynamic or other side effects were detected.

\section{Statistical analysis}

Mean values were calculated for WOB, PTP, $\Delta P_{\text {oes, }}$ $P 0.1$, PEEPi, $V \mathrm{~T}, f \mathrm{R}, t \mathrm{t} / t$ tot and TTI. Differences between the ventilatory modes were tested using analysis of variance and nonparametric methods (Friedman test). In order to identify homogenous subgroups, post hoc tests according to the method of Duncan were performed. A paired t-test was used to evaluate the differences between the Plow phases of BiPAP and CPAP. A p-value of $<0.05$ was considered significant.

\section{Results}

The ventilatory variables and blood gas tension measured at each intervention in this study are listed in table 2 . $V$ T showed significantly higher values during PS, but no significant differences between BiPAP and CPAP. $f R$ was not significantly different between the three methods. $t \mathrm{I} /$ $t$ tot was significantly lower with PS, but did not differ between BiPAP and CPAP. Concerning the TTI, there was a significant difference between PS and CPAP, BiPAP lying between these groups. Oxygenation showed no significant difference, but the $P \mathrm{a}, \mathrm{CO}_{2}$ was significantly lower during PS compared with BiPAP and CPAP. Patients' WOB, PTP, $\triangle P_{\text {oes }}$ and $P 0.1$ were significantly lower during PS than during BiPAP, and significantly lower with BiPAP than with CPAP. PEEPi was the same during PS and CPAP, but significantly higher during BiPAP.

In a more detailed analysis of these results, only the $P$ low phases of BiPAP and CPAP were compared. The main data is shown in table 3. Differences in WOB and PTP were found, but they were not statistically significant. $V \mathrm{~T}$ was significantly lower during the Plow phases of BiPAP than during CPAP. The quotients $\mathrm{WOB} / V \mathrm{~T}$ and $\mathrm{PTP} / V \mathrm{~T}$ were significantly higher during the Plow BiPAP than during
CPAP. PEEPi had significantly higher values during $P$ low BiPAP compared to CPAP

Figure 2 shows WOB measured breath by breath in a representative patient. The phases of registration during all three ventilatory modes are superimposed in one diagram. WOB is not only clearly lower with PS, but also shows a uniform pattern according to the equal support of every breath (the values from one breath to the next do not differ much). BiPAP, in contrast, obviously has greater variance in its data, resulting from the unequal support mechanisms, which will be discussed later.

Figure 3 shows the PTP of another single patient superimposed in the same way. The PTP with PS first decreased slightly and then remained stable over the measurement period. The PTP with BiPAP and also with CPAP increased steadily up to high values until the patient became exhausted and could no longer stay on these ventilatory modes. Figure 3 also demonstrates the inhomogeneous pattern of the PTP during BiPAP compared with the smooth one during PS.

\section{Discussion}

The unrestricted spontaneous breaths during pressurecontrolled mechanical ventilation are the main feature of BiPAP and advantageous in diseases such as ARDS or during the weaning of postsurgery patients. The main finding of the present study for COPD patients, however, is that BiPAP is disadvantageous due to these spontaneous breaths. As long as a COPD patient is sedated and not breathing spontaneously, BiPAP can be used safely as a means of pressure-controlled mechanical ventilation (fig. 1a), which can be perfectly adapted to the special pathophysiology of the COPD patient. However, as soon as the patient starts breathing spontaneously (fig. 1b), two negative effects occur: first, the breaths at Phigh lead to hyperinflation and secondly, unsupported breaths put an increased burden on the respiratory muscles. Reducing thigh might decrease PEEPi, but thigh would then be too short to allow spontaneous breaths to occur, a main feature of BiPAP. A thigh of $\geq 2 \mathrm{~s}$ is recommended for BiPAP in order to make sure that the patient really breathes

Table 2. - Ventilatory parameters and blood gas tensions

\begin{tabular}{|c|c|c|c|c|}
\hline & BiPAP & PS & CPAP & Homogenous groups* \\
\hline WOB $\cdot \mathrm{L}^{-1} \mathrm{~J} \cdot \mathrm{L}^{-1}$ & $1.03 \pm 0.57$ & $0.62 \pm 0.47$ & $1.3 \pm 0.51$ & All three groups sig diff \\
\hline PTP $\mathrm{cmH}_{2} \mathrm{O} \cdot \mathrm{s} \cdot \mathrm{min}^{-1}$ & $222.6 \pm 130$ & $152.1 \pm 115$ & $280.4 \pm 117$ & All three groups sig diff \\
\hline$\Delta P_{\text {oes }} \mathrm{cmH}_{2} \mathrm{O}$ & $14.4 \pm 5.9$ & $10.3 \pm 5.4$ & $16.3 \pm 6.0$ & All three groups sig diff \\
\hline$P_{0.1} \mathrm{cmH}_{2} \mathrm{O}$ & $5.23 \pm 3.1$ & $3.52 \pm 2.1$ & $6.06 \pm 3.1$ & All three groups sig diff \\
\hline PEEPi $\mathrm{cmH}_{2} \mathrm{O}$ & $4.14 \pm 3.0$ & $3.0 \pm 3.1$ & $3.0 \pm 2.3$ & (PS, CPAP) versus (BIPAP) \\
\hline$V$ T L & $0.40 \pm 0.19$ & $0.46 \pm 0.13$ & $0.37 \pm 0.12$ & (BiPAP, CPAP) versus (PS) \\
\hline$f \mathrm{R}$ breaths $\cdot \mathrm{min}^{-1}$ & $26.6 \pm 6.5$ & $26.1 \pm 6.2$ & $28.7 \pm 8.5$ & No sig diff \\
\hline$t \mathrm{I} /$ tot & $0.40 \pm 0.04$ & $0.36 \pm 0.05$ & $0.39 \pm 0.05$ & (BiPAP, CPAP) versus (PS) \\
\hline TTI & $0.12 \pm 0.06$ & $0.08 \pm 0.04$ & $0.17 \pm 0.14$ & (PS, BiPAP) versus (BiPAP, CPAP) \\
\hline $\mathrm{Pa}_{\mathrm{a}, \mathrm{O}_{2}} \mathrm{mmHg}$ & $105.9 \pm 25.9$ & $98.1 \pm 23.2$ & $105.8 \pm 24.8$ & No sig diff \\
\hline $\mathrm{Pa}_{\mathrm{a}} \mathrm{CO}_{2} \mathrm{mmHg}$ & $47.0 \pm 13.9$ & $43.6 \pm 11.6$ & $47.4 \pm 11.9$ & (BiPAP, CPAP) versus (PS) \\
\hline
\end{tabular}

*: post hoc tests (Duncan): homogeneous groups in brackets show no significant difference. Data are presented as mean $\pm \mathrm{SD}(\mathrm{n}=21)$. BiPAP: biphasic positive airway pressure; PS: pressure support; CPAP: continuous positive airway pressure; WOB: work of breathing; PTP: pressure-time product; $\Delta P$ oes: change in oesophageal pressure from end expiration to end inspiration; $P 0.1$ : airway occlusion pressure; PEEPi: intrinsic positive end-expiratory pressure; $V \mathrm{~T}$ : tidal volume; $f \mathrm{R}$ : respiratory frequency; $t \mathrm{I} / t$ tot: ratio of inspiratory time to breath cycle duration; TTI: tension-time index; $\mathrm{Pa}, \mathrm{O}_{2}$ : oxygen tension; $\mathrm{Pa}_{\mathrm{a}} \mathrm{CO}_{2}$ : arterial carbon dioxide tension. sig diff: significant difference. $(1 \mathrm{mmHg}=0.133 \mathrm{kPa}$.) 
Table 3. - Ventilatory parameters of the biphasic positive airway pressure (BiPAP) lower positive end-expiratory pressure (PEEP) level (Plow) and continuous positive airway pressure (CPAP)

\begin{tabular}{lccc}
\hline & BiPAP Plow & CPAP & p-value* \\
\hline WOB $\cdot \mathrm{L}^{-1} \mathrm{~J} \cdot \mathrm{L}^{-1}$ & $1.19 \pm 0.57$ & $1.30 \pm 0.51$ & $\mathrm{NS}$ \\
$\mathrm{PTP} \mathrm{cmH} \mathrm{H}_{2} \mathrm{O} \cdot \mathrm{s} \cdot \mathrm{min}^{-1}$ & $305.2 \pm 129.5$ & $294.7 \pm 120.9$ & $\mathrm{NS}$ \\
$V \mathrm{~T} \mathrm{~L}$ & $0.28 \pm 0.09$ & $0.37 \pm 0.12$ & $<0.001$ \\
$\mathrm{WOB} / V_{\mathrm{T}}$ & $4.68 \pm 2.6$ & $4.01 \pm 2.5$ & $<0.05$ \\
$\mathrm{PTP} / V \mathrm{~T}$ & $1191 \pm 604$ & $913 \pm 571$ & $<0.001$ \\
$\mathrm{PEEPi} \mathrm{cmH}_{2} \mathrm{O}$ & $3.97 \pm 2.8$ & $3.0 \pm 2.3$ & $<0.05$ \\
\hline
\end{tabular}

*: paired t-test. Data are presented as mean $\pm \mathrm{SD}(\mathrm{n}=21)$. WOB: work of breathing; PTP: pressure-time product; VT: tidal volume; PEEPi: intrinsic PEEP.

spontaneously at $P$ high [8]. Another suggestion for adapting BiPAP to spontaneously breathing COPD patients might be the reduction of $t$ low, too, thus increasing ventilatory support. Both adjustments lead to "pressure support-like" ventilation, with a short push of high pressure being given to as many breaths as possible. Besides the fact that it is virtually impossible to support every single breath with fixed time cycling (patients change their $f \mathrm{R} !$ ), this type of ventilation cannot be called BiPAP because it lacks the essential feature of BiPAP, namely unrestricted spontaneous breaths at both pressure levels during pressure-controlled mechanical ventilation. The aim of the present study was to measure the effects of "classical" BiPAP in COPD patients. Although the pathophysiological theories based on the studies of PETROF et al. [1] and RANIERI et al. [31] indicate that BiPAP may not be an appropriate mode for COPD patients, it has so far never been demonstrated. This study provides, for the first time, measurements of respiratory muscle effort and hyperinflation in COPD patients during BiPAP.

The comparison of PS and BiPAP is an interesting subject, which has attracted several authors [11, 16, 32-34]. Various effects on haemodynamics $[11,32]$, gas exchange [11], oxygen cost of breathing [33] and weaning outcome $[32,33]$ were studied. However, none of these studies investigated respiratory muscle effort in spontaneously breathing COPD patients.

BiPAP offers only a small proportion of assisted breaths: those breaths that are initiated in the last $25 \%$ of $t$ low can trigger the switch to Phigh and serve therefore as a kind of "pressure support". All other breaths on BiPAP are nothing more than unsupported CPAP breaths. Thus PS, which assists every single breath, is more effective than BiPAP in reducing respiratory muscle effort. In the present study PTP, WOB, $\Delta P_{\text {oes }}$ and $P 0.1$ had their lowest values during the PS phase, in which the largest $V T$ were also generated. This explains why the carbon dioxide clearance with PS was better than with the two other modes.

The continuously changing PEEP levels signify different conditions for each breath for the patient, thus resulting in a great variation in the efforts to be attempted. This becomes evident in the inhomogeneous pattern of PTP and WOB varying from breath to breath as shown in figures 2 and 3 . Such an unequal pattern is an energy-consuming way of breathing and often uncomfortable for the patients.

Further, BiPAP enhances the development of PEEPi in COPD patients. The time-cycling mechanism does not allow patient-controlled free expiration, but superimposes mandatory volume changes. Breathing spontaneously at $P$ high, the patient is only permitted to exhale to $P$ high. It is known from the studies of PETROF et al. [1] and RANIERI et al. [31] that COPD patients become hyperinflated as a result of externally applied PEEP that exceeds the present PEEPi. Therefore, a significantly higher PEEPi was measured on BiPAP than on PS and CPAP. That the Phigh phases are really responsible for hyperinflating the patient was clearly shown in the comparison between the BiPAP $P$ low phases and CPAP. Although the pressures of BiPAP $P$ low and CPAP were equal, a significantly higher PEEPi was found during BiPAP Plow. The previously applied mandatory Phigh phases hyperinflate the COPD patient due to the high external PEEP, and, because of the expiratory flow limitation, the patient is unable to quickly get rid of the trapped volume and presents with increased PEEPi on the following Plow phase. Consequently, during the Plow phase the respiratory muscles are strained and the patients reduce their $V \mathrm{~T}$ in order to avoid muscle fatigue. If WOB and PTP are calculated for the generated $V \mathrm{~T}$ (quotients $\mathrm{WOB} / V \mathrm{~T}$ and $\mathrm{PTP} / V \mathrm{~T}$ ) the respiratory muscle effort is significantly higher during BiPAP Plow than during CPAP.

Flow-limited COPD patients do not become hyperinflated as a result of externally applied PEEP so long as the PEEP levels do not reach or exceed the intrinsic PEEP.

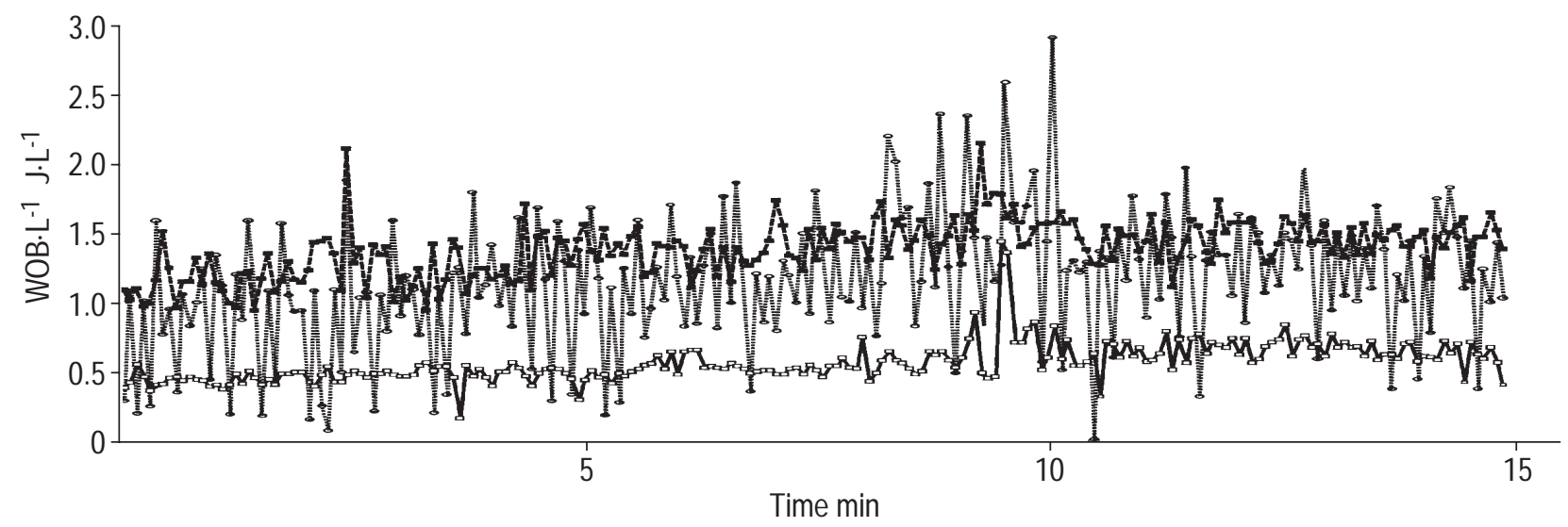

Fig. 2. - Work of breathing (WOB) $\mathrm{L}^{-1}$ measured breath by breath in patient No. 13. $\square$ : continuous positive airway pressure; $\square$ : pressure support; $\bigcirc$ : biphasic positive airway pressure (BiPAP). Note the inhomogeneous pattern of $\mathrm{WOB} \cdot \mathrm{L}^{-1}$ during BiPAP. 


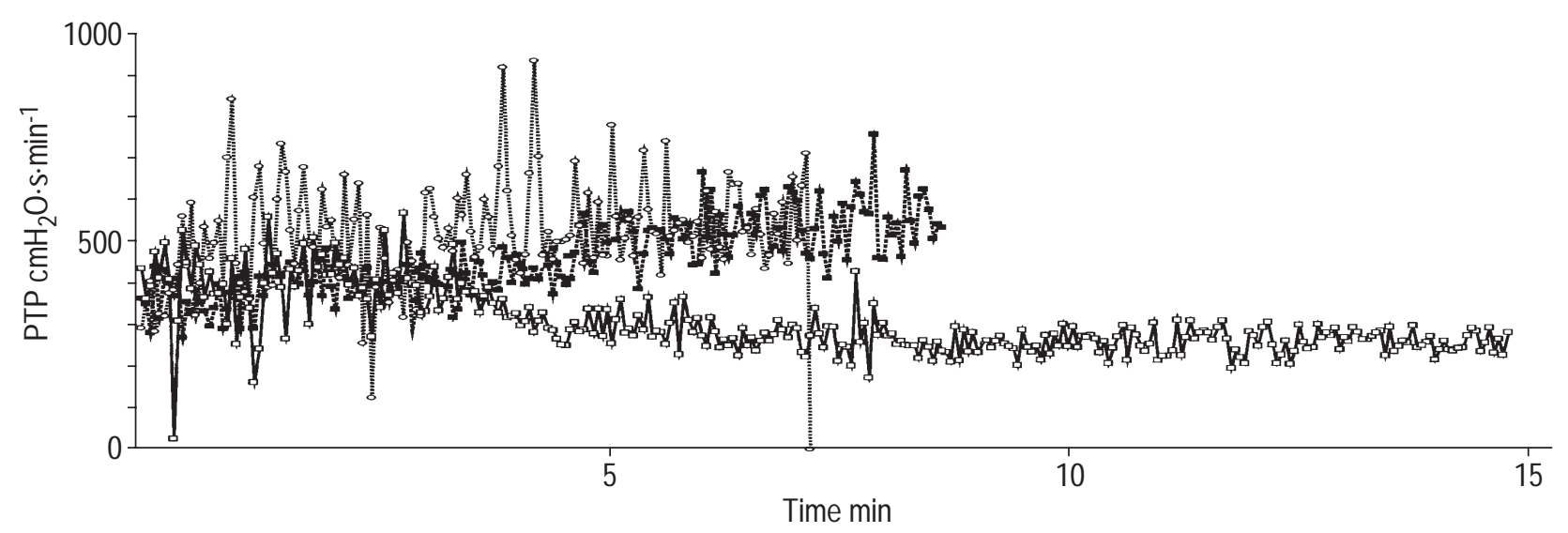

Fig. 3. - Pressure-time product (PTP) measured breath by breath in patient No. 9. $\mathbf{\square}$ : continuous positive airway pressure (CPAP); $\square$ : pressure support (PS); $\bigcirc$ : biphasic positive airway pressure (BiPAP). Only PS was tolerated for $15 \mathrm{~min}$; BiPAP and CPAP were interrupted because of exhaustion.

The "optimal PEEP level" of COPD patients depends on their PEEPi: Plow do not provide maximum reduction of the inspiratory work load; Phigh lead to further hyperinflation. BiPAP works with two PEEP levels instead of one "optimal", which the authors suppose is disadvantageous.

Indeed, there are some limitations to the present study. For the calculations of respiratory mechanics, the BICORE system was used. Although this has been used in several studies [16-18], there are some concerns about the measurements. For instance, chest wall compliance is not measured, but assumed to be $200 \mathrm{~mL} \cdot \mathrm{cmH}_{2} \mathrm{O}^{-1}$. Further, the reliability of the PEEPi measurements have not yet been tested. Still, the authors believe that the present application was justified because different ventilatory modes were compared with the same method in the same patient. Another limitation of the study is the fact that only one specific ventilator setting was used with the main aim of equal mean pressures for BiPAP and PS. It cannot be excluded that with other ventilator settings the results could vary.

CALzIA et al. [16] reported higher PTPs during BiPAP than during PS in patients after aortocoronary bypass surgery, but they did not find a difference in WOB between the two groups. Further parameters of respiratory muscle effort were not measured. In the present study, WOB also showed significant differences. COPD patients are more sensitive to inappropriate ventilatory modes because of the expiratory flow limitation and the reduced efficiency and overall power of their inspiratory muscles. Regarding TTI, six patients had a TTI of $>0.15$ during BiPAP, whereas only two of them also had a slightly elevated TTI during PS. Four patients could not even endure BiPAP for $15 \mathrm{~min}$, although they were stable on PS with equal levels of pressure. All of the patients had elevated $P_{0.1}$ during BiPAP, demonstrating higher respiratory drive. The present authors agree with CALZIA et al. [16] that BiPAP is more exhausting than PS, but add that it is especially dangerous for COPD patients.

In conclusion, biphasic positive airway pressure carries the risk of increased work of breathing in chronic obstructive pulmonary disease patients under certain settings, because it does not support the respiratory muscles sufficiently, but even burdens them by promoting dynamic hyperinflation. Pressure support is still the superior venti- latory assistance mode for reducing respiratory muscle effort in chronic obstructive pulmonary disease patients.

\footnotetext{
Acknowledgements. The authors thank W. Grossmann of the Dept of Statistics, Operations Research and Computer Science, University of Vienna for calculating the statistics. The authors also thank T. Papatheophilou for help with the electronic data processing, F. Proudman for help with the editing, the intensive care unit nurses for their assistance and the patients for their cooperation.
}

\section{References}

1. Petrof BJ, Legare M, Goldberg P, Milic-Emili J, Gottfried SB. Continuous positive airway pressure reduces work of breathing and dyspnea during weaning from mechanical ventilation in severe chronic obstructive pulmonary disease. Am Rev Respir Dis 1990; 141: 281-289.

2. Brochard L, Harf A, Lorino H, Lemaire F. Inspiratory pressure support prevents diaphragmatic fatigue during weaning from mechanical ventilation. Am Rev Respir Dis 1989; 139: 513-521.

3. Kacmarek RM. The role of pressure support ventilation in reducing work of breathing. Respir Care 1988; 33: 99120.

4. Tokioka H, Saito S, Kosaka F. Effect of pressure support ventilation on breathing patterns and respiratory work. Intensive Care Med 1989; 15: 491-494.

5. Fiastro JF, Habib MP, Quan SF. Pressure support compensation for inspiratory work due to endotracheal tubes and demand continuous positive airway pressure. Chest 1988; 93: 499-505.

6. Appendini L, Patessio A, Zanaboni S, et al. Physiologic effects of positive end-expiratory pressure and mask pressure support during exacerbations of chronic obstructive pulmonary disease. Am J Respir Crit Care Med 1994; 149: 1069-1076.

7. Nava S, Ambrosino N, Rubini F, et al. Effect of nasal pressure support ventilation and external PEEP on diaphragmatic activity in patients with severe stable COPD. Chest 1993; 103: 143-15.

8. Baum M, Benzer H, Putensen C, Koller W, Putz G. Biphasic positive airway pressure (BiPAP) - eine neue Form der augmentierenden Beatmung. Anaesthesist 1989; 38: 452-45.

9. Hörmann C, Baum M, Putensen C, Kleinsasser A, Benzer 
H. Effects of spontaneous breathing with BiPAP on pulmonary gas exchange in patients with ARDS. Acta Anaesthesiol Scand Suppl 1997; 111: 152-155.

10. Putensen C, Rasanen J, Lopez FA. Ventilation-perfusion distributions during mechanical ventilation with superimposed spontaneous breathing in canine lung injury. $\mathrm{Am}$ J Respir Crit Care Med 1994; 150: 101-108.

11. Putensen C, Räsänen J, Lopez FA. Interfacing between spontaneous breathing and mechanical ventilation affects ventilation-perfusion distributions in experimental bronchoconstriction. Crit Care Med 1995; 151: 993-999.

12. Sydow M, Burchardi H, Ephraim E, Zielmann S, Crozier TA. Long-term effects of two different ventilatory modes on oxygenation in acute lung injury. Comparison of airway pressure release ventilation and volume-controlled inverse ratio ventilation. Am J Respir Crit Care Med 1994; 149: $1550-1556$.

13. Rathgeber J, Schorn B, Falk V, Kazmayer S, Spiegel T, Burchardi $\mathrm{H}$. The influence of controlled mandatory ventilation (CMV), intermittent mandatory ventilation (IMV) and biphasic intermittent positive airway pressure (BiPAP) on duration of intubation and consumption of analgesics and sedatives. A prospective analysis in 596 patients following adult cardiac surgery. Eur J Anaesthesiol 1997; 14: 576-582.

14. Kiehl M, Schiele C, Stenzinger W, Kienast J. Volumecontrolled versus biphasic positive airway pressure ventilation in leucopenic patients with severe respiratory failure. Crit Care Med 1996; 24: 780-784.

15. Hörmann C, Baum M, Putensen C, Mutz NJ, Benzer H. Biphasic positive airway pressure (BiPAP) - a new mode of ventilatory support. Eur J Anaesthesiol 1994; 11: 3742.

16. Calzia E, Lindner KH, Witt S, et al. Pressure-time product and work of breathing during biphasic continuous positive airway pressure and assisted spontaneous breathing. Am J Respir Crit Care Med 1994; 150: 904-910.

17. Petros AJ, Lamond CT, Bennett D. The Bicore pulmonary monitor. A device to assess the work of breathing while weaning from mechanical ventilation. Anaesthesia 1993; 48: 985-988.

18. Blanch PB, Banner MJ. A new respiratory monitor that enables accurate measurement of work of breathing: a validation study. Respir Care 1994; 39: 897-905.

19. Baydur A, Behrakis PK, Zin WA, Jaeger M, Milic-Emili J. A simple method for assessing the validity of the oesophageal balloon technique. Am Rev Respir Dis 1982; 126: 788-791.

20. Pepe PE, Marini JJ. Occult positive end-expiratory pressure in mechanically ventilated patients with airflow obstruction. The auto-PEEP effect. Am Rev Respir Dis 1982; 126: $166-170$.
21. Heindl W, Kapfhammer G. Die Messung des intrinsic PEEP bei spontanatmenden COPD-Patienten. Intensivmed 1989; 26: 284-289.

22. Haluszka J, Chartrand DA, Grassino A, Milic-Emili J. Intrinsic PEEP and arterial pCO2 in stable patients with chronic obstructive pulmonary disease. Am Rev Respir Dis 1990; 141: 1194-1197.

23. Derenne JP, Fleury B, Pariente R. Acute respiratory failure of chronic obstructive pulmonary disease. Am Rev Respir Dis 1988; 138: 1006-1033.

24. Sassoon CSH, Te TT, Mahutte CK, Light RW. Airway occlusion pressure. An important indicator for successful weaning in patients with chronic obstructive pulmonary disease. Am Rev Respir Dis 1987; 135: 107-113.

25. Fiastro JF, Habib MP, Shon BY, Campbell SC. Comparison of standard weaning parameters and the mechanical work of breathing in mechanically ventilated patients. Chest 1988; 94: 232-238.

26. Fleury B, Murciano D, Talamo C, Aubier M, Pariente R, Milic-Emili J. Work of breathing in patients with chronic obstructive pulmonary disease in acute respiratory failure. Am Rev Respir Dis 1985; 131: 822-827.

27. Collett PW, Perry C, Engel LA. Pressure-time product, flow, and oxygen cost of resistive breathing in humans. $J$ Appl Physiol 1985; 58: 1263-1272.

28. Bellemare F, Grassino A. Effect of pressure and timing of contraction on human diaphragm fatigue. J Appl Physiol 1982; 53: 1190-1195.

29. Vaz Fragoso CA. Monitoring in adult critical care. In: Kacmarek RM, Hess D, Stoller JK, eds. Monitoring in Respiratory Care. St. Louis, MO, Mosby Year Book, 1993; pp. 649-688.

30. Bellemare F, Grassino A. Force reserve of the diaphragm in patients with chronic obstructive pulmonary disease. $J$ Appl Physiol 1983; 55: 8-15.

31. Ranieri VM, Giuliani R, Cinnella G, et al. Physiologic effects of positive end-expiratory pressure in patients with chronic obstructive pulmonary disease during acute ventilatory failure and controlled mechanical ventilation. $\mathrm{Am}$ Rev Respir Dis 1993; 147: 5-13.

32. Schirmer U, Calzia E, Lindner KH, Goertz A, Georgieff M. Right ventricular function during weaning from resprator after coronary artery bypass grafting. Chest 1994; 105: 1352-1356.

33. Staudinger T, Kordova H, Röggla M, et al. Comparison of oxygen cost of breathing with pressure-support ventilation and biphasic intermittent positive airway pressure ventilation. Crit Care Med 1998; 26: 1518-1522.

34. Viale JP, Duperret S, Mahul P, et al. Time course evolution of ventilatory responses to inspiratory unloading in patients. Am J Respir Crit Care Med 1998; 157: $428-434$. 